\title{
CORRIGENDUM
}

\section{Attraction of Callosobruchus maculatus (F.) \\ (Coleoptera: Bruchidae) to four varieties of Lathyrus sativus L. seed volatiles - CORRIGENDUM}

\author{
P. Adhikary, A. Mukherjee and A. Barik
}

doi: 10.1017/S000748531400087X, Published by Cambridge University Press, 19 December 2014.

The authors apologise for errors within Figure 9B, which appears on page 198 of Volume 105, Issue 2. The corrected version is given below.

A 3-Octanone

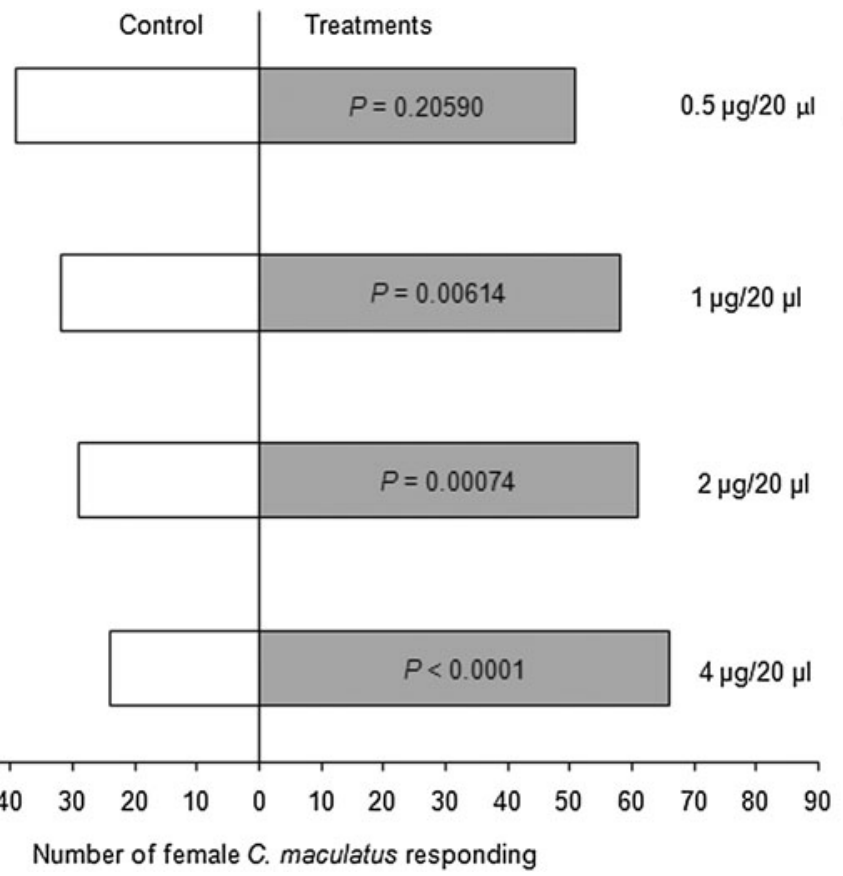




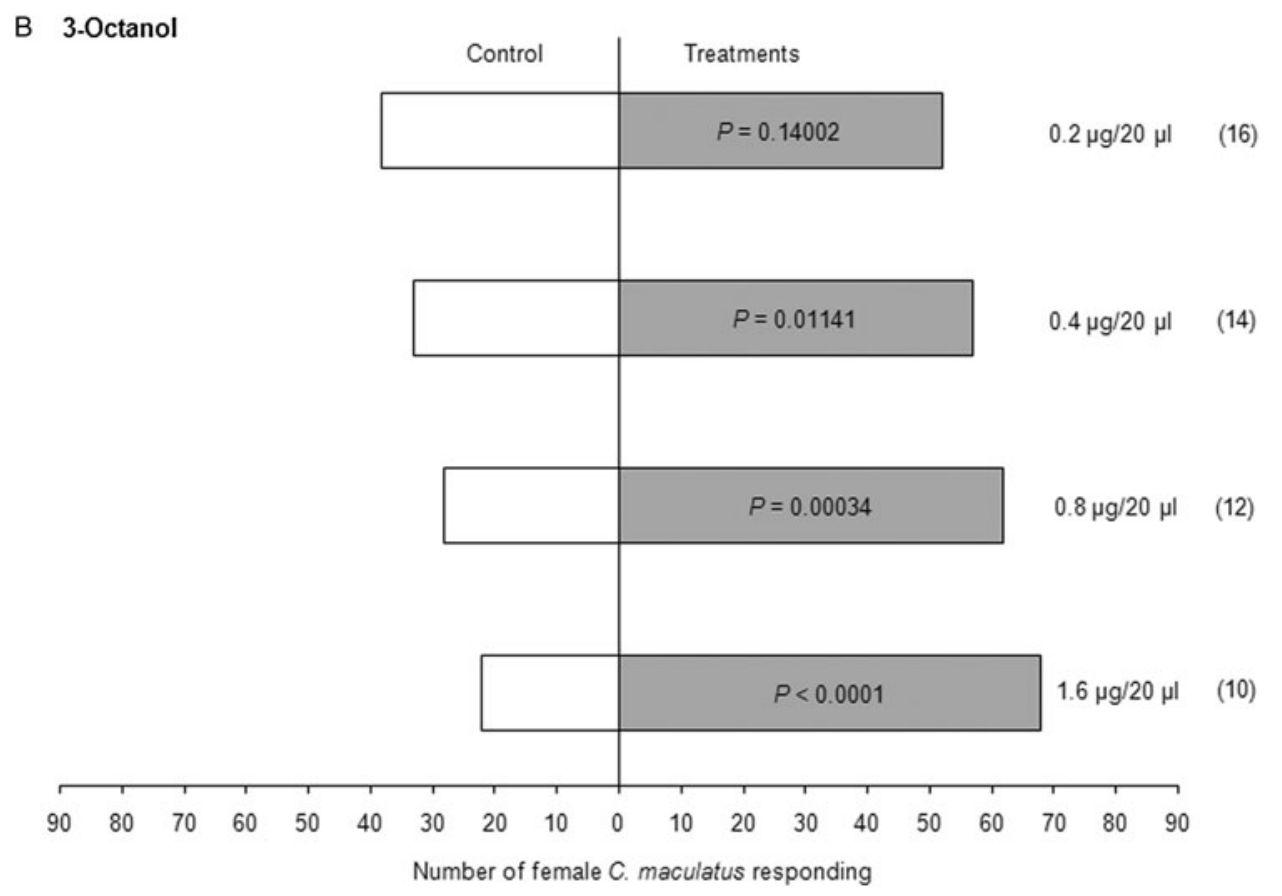

\section{Reference}

P. Adhikary, A. Mukherjee and A. Barik. Attraction of Callosobruchus maculatus (F.) (Coleoptera: Bruchidae) to four varieties of Lathyrus sativus L. seed volatiles. Bulletin of Entomological Research 105, 187-201. 